\title{
Arqueología de las Islas Canarias
}

\author{
Juan Francisco Navarro Mederos*
}

\begin{abstract}
RESUMEN ABSTRACT
Presentamos cómo ha evolucionado la We present in this paper the evolution ciencia arqueológica en las Islas of the Archaeological Science on the Canarias y la situación actual de la Canary Islands and its present

disciplina. A continuación nos situation. Indeed we plant the most centramos en algunos de los temas claves de su prehistoria: los grandes problemas en torno al poblamiento antiguo del Archipiélago y la variabilidad cultural entre las islas. important problems about the arrival of the ancient Berberian peoples to the archipielago and the cultural variations between them, which has been watched in the seven islands.
\end{abstract}

\section{PALABRAS CLAVES KEYWORDS}

Islas Canarias, Prehistoria, Canary Islands, Prehistory, Arqueología, Poblamientos Insulares. Archaeology, Islands Colonization.

\section{PASADO Y PRESENTE DE LA ARQUEOLOGÍA CANARIA}

\subsection{El pasado}

La arqueología canaria es singular en la medida en que tiene como objeto de estudio unas culturas insulares, con procesos específicos, vin-

\footnotetext{
* Departamento de Prehistoria, Antropología e Historia Antigua. Universidad de La Laguna.
} 
culadas a un ámbito geográfico y cultural ajeno al ibérico y, por tanto, con problemas metodológicos particulares (C. del Arco, M.C. Jiménez y J.F. Navarro, 1992; L. Diego, 1972 y 1977; R. González y A. Tejera, 1986; M.S. Hernández, 1984; C. Martín, 1984). La disciplina ha tenido en el Archipiélago una trayectoria más que centenaria, que en ciertos aspectos y épocas discurrió por cauces semejantes al resto del Estado, aunque también ha conocido períodos en que estuvo más vinculada a tendencias, escuelas, intereses científicos o instituciones de otros países, como sucedió en la etapa inicial.

Sus preludios precientíficos abarcan un segmento temporal comprendido entre finales del siglo $x V$ y mediados del $x i x$, marcado por el anticuarismo, que al principio sólo conoció esporádicas y tímidas manifestaciones. A finales del período esta tendencia se hizo más evidente, ya que en unos pocos individuos puede hablarse de "anticuarismo científico", con una observación de los restos algo más detenida, y algunos objetos y restos humanos antiguos empezaron a figurar en los gabinetes de eruditos. Las momias despertaban una curiosidad mayor y, desde el siglo xVII, empezó a crecer progresivamente el interés por ellas y su exportación a países europeos.

Sabin Berthelot tuvo un protagonismo de excepción en el final de esa etapa y fue el precursor de la antropología y la arqueología canaria. Interpretó la sociedad aborigen desde la actitud nostálgica del romanticismo y contribuyó a propagar la imagen del guanche como buen salvaje, que ha durado en buena medida hasta la actualidad. Hacia 1840 empezó a publicar sobre los antiguos habitantes, aunque usando sólo las fuentes etnohistóricas; luego fue el primero en interesarse por la naciente antropología biológica y la arqueología, de manera que a partir de 1860 empezó a publicar sobre estos temas, seguido de otros investigadores canarios más jóvenes. Su última obra, Antiquités Canariennes (1879), fue el primer libro de carácter enteramente arqueológico.

De hecho el nacimiento de la arqueología canaria se gestó, no sólo por influencia de Berthelot, sino porque en las islas existía un ambiente intelectual favorable a ello y porque llegaron los ecos de fenómenos análogos que se estaban produciendo en Europa. En ese caldo de cultivo, pequeños grupos de intelectuales en Gran Canaria, Tenerife y La Palma dirigieron su interés hacia los vestigios materiales del pasado, deseosos de conocer a través de ellos el modo de vida de los antiguos canarios. Era común a todos ellos un espíritu patriota de recuperación de las raíces, su juventud discurrió durante el romanticismo y se esforzaron por obtener una sólida formación universitaria. Los más fieles representantes de esta 
generación eran médicos de profesión, que habian asumido los más avanzados postulados científicos, como el darwinismo.

Crearon tres sociedades científicas: el Gabinete Científico (Tenerife, 1877), El Museo Canario (Gran Canaria, 1879) y la Sociedad La Cosmológica (La Palma, 1881), cuyo objetivo era fomentar el conocimiento de las ciencias, las letras y las artes, con especial referencia a la historia y la prehistoria del Archipiélago, para lo cual, entre otras cosas, se fundaron otros tantos museos. De aquellas vetustas instalaciones hoy se conserva el Museo Canario; el Gabinete Científico desapareció y sus fondos constituyeron el germen del Museo Arqueológico de Tenerife; mientras que La Cosmológica sobrevive, aunque sus colecciones recientemente han pasado a integrarse en el Museo Insular.

De aquella generación destacaron Juan Bethencourt Alfonso y Gregorio Chil y Naranjo. J. Bethencourt era responsable de la Sección de Antropología y Arqueología Prehistórica de Canarias, la más activa del Gabinete Científico. Le quedaban resabios románticos y estaba muy apegado a su tierra. Por eso fue, sobre todo, un gran investigador de campo, que combinaba las prospecciones y excavaciones arqueológicas con los estudios etnográficos, y a veces no establecía distinción clara entre ambas disciplinas, pues consideraba que una buena parte del campesinado isleño atesoraba la memoria histórica de los guanches. Recientemente se ha publicado se gran obra Historia del Pueblo Guanche, que constituye una importantísima fuente de información, por el cúmulo de datos que aporta, aunque sus interpretaciones sobre el origen y el parentesco cultural de los antiguos canarios no resisten hoy la más leve crítica.

G. Chil fue el primer director del Museo Canario. Durante su mandato y hasta los inicios de este siglo, en el Museo se investigaba con intensidad, acogiendo a diversos antropólogos, entre los que sin duda destaca la figura de René Verneau, atraídos por la presencia de rasgos cromañoides entre la población prehistórica de las islas. Chil poseía una sólida formación científica como historiador y antropólogo, siendo un investigador bastante activo y relacionado con círculos académicos franceses antes de surgir el Museo. Era un hombre de su tiempo: claramente positivista, que pretendía reconstruir la prehistoria con todos los medios de que disponía la ciencia, en el que subyacían los postulados de la arqueología racista. Fue más un investigador de gabinete que de campo, en lo que sin embargo descollaba el conservador Víctor Grau-Bassas y Mas, muy preocupado por registrar el contexto de los hallazgos.

Después de ese impetuoso arranque que duró toda una generación, la arqueología canaria padeció un largo período de languidez. Durante las 
cuatro primeras décadas del siglo xx disminuyó la intensidad de las investigaciones, marcadas cada vez más por posiciones teóricas como el difusionismo y, en general, por los postulados propios de la escuela histórico-cultural, que tendrán una larga implantación (R. González y A. Tejera, 1986).

En 1942 se inauguró la etapa del Comisariado de Excavaciones Arqueológicas, dando lugar a una fuerte revitalización de las actividades arqueológicas $y$, aunque algunos tópicos de la vertiente negativa de ese período sean extensibles al Archipiélago, debemos reconocer que aquí tuvo cierta repercusión positiva e incluso singularmente enriquecedora. La mayor parte de este período estuvo marcado por las figuras de Luis Diego Cuscoy y Sebastián Jiménez Sánchez, quienes desarrollaron la mayoría de la labor investigadora y patrimonial en las provincias de Santa Cruz de Tenerife y Las Palmas de Gran Canaria, respectivamente. Sobre ellos ejerció cierta influencia el catedrático de La Laguna Elías Serra Ráfols, alumno de P. Bosch Gimpera y gran maestro de historiadores canarios. Pero, sobre todo, durante mucho tiempo pesó la tutela de Julio Martínez Santaolalla, quien inculcó un objetivo concreto: darle a la prehistoria canaria una visión secuencial, cosa que no lograron; y un método: ordenar las evidencias según esquemas tipológicos, para luego distribuirlas cronológicamente.

S. Jiménez Sánchez y L. Diego Cuscoy representaron dos maneras bien distintas de hacer arqueología. El primero quedó anquilosado, por lo que sus trabajos de campo y sus publicaciones acusaban notables deficiencias; cabe destacar una ardua labor de prospección en las islas orientales y algunas "campañas de limpieza» para sacar a la luz grandes conjuntos arqueológicos (figura 1). Por el contrario, L. Diego constituyó un paradigma de constante superación y en muchos aspectos se adelantó a su tiempo. Fue poeta, etnógrafo, historiador y, sobre todo, arqueólogo. Comenzó participando activamente en los Planes Nacionales del Comisariado, buscando escondrijos con cerámica en los campos de pastoreo estacional y cuevas sepulcrales, que suministraban espectaculares ajuares cerámicos y restos humanos, respectivamente. Pero a fines de los cincuenta ya se planteaba cuestiones teóricas y metodológicas, como la etnología comparada y el determinismo ambiental: consideraba a los guanches como pastores que se comportaban de forma análoga a los viejos cabreros tinerfeños que él entrevistaba, cuyo modo de vida estaría muy condicionado por el medio natural. No se detuvo ahí, sino que rápidamente evolucionó atraído por varias tendencias y acabó adoptando una postura ecléctica. 


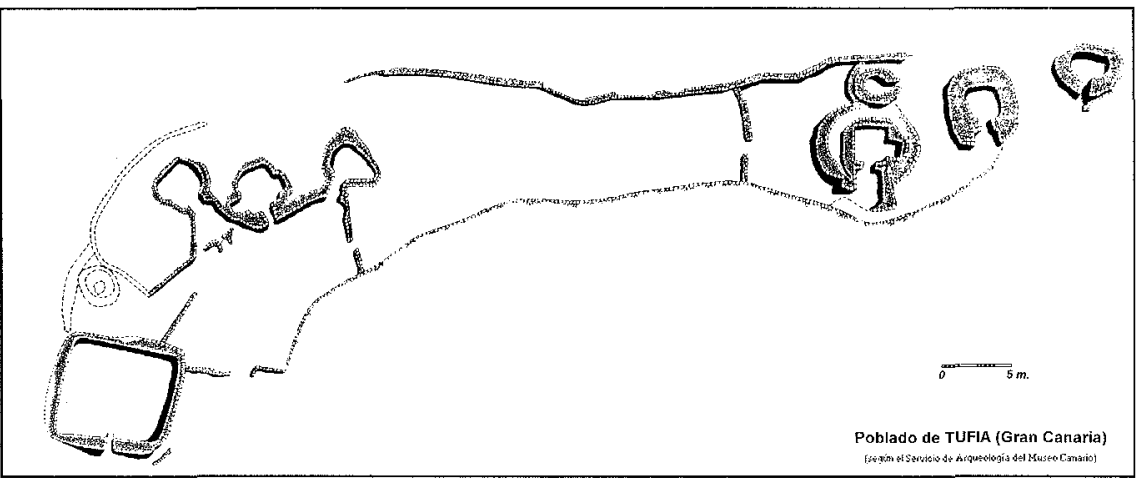

Figura 1. El poblado de Tufia es un ejemplo de conjunto exhumado y parcialmente reconstruido por el Comisariado de Excavaciones.

Mientras, los estudios de antropología física de Miguel Fusté e Ilse Schwidetzky impactarían fuertemente en el enfoque que los investigadores y, en general, la población canaria darían al problema de los orígenes del poblamiento y a la configuración de la variabilidad cultural; planteando la presencia de dos tipos humanos — cromañoides y mediterranoides-, que habrían llegado a Canarias en épocas muy distintas y, en consecuencia, portando culturas arcaicas los primeros y más desarrolladas los segundos. De esta manera, el problema de la prehistoria canaria empezaba a explicarse bajo la perspectiva de la dicotomía racial y la asociación entre raza y cultura, planteamientos que tardarían algún tiempo en superarse.

\subsection{El presente}

En la década de los setenta, la disciplina acaba por integrase al ámbito universitario, llegando a alcanzar una definitiva consolidación cuando se creó el Departamento de Arqueología y Prehistoria de la Universidad de La Laguna ${ }^{1}$, que hacía posible la formación de especialistas y aseguraba la prosecución de un quehacer científico hasta entonces marcado por la

El Departamento de Prehistoria y Arqueología se creó en 1969 con esas dos áreas, y posteriormente se amplió con la incorporación las áreas de Historia Antigua y Antropología Social, adoptando por nombre el de Dpto. de Prehistoria, Antropología e Historia Antigua. Hace unos años se creó la Universidad de Las Palmas de Gran Canaria, cuya área de Prehistoria está integrada en el Dpto. de Ciencias Históricas. 
discontinuidad. Sus fundadores - Manuel Pellicer y Pilar Acosta- diseñaron una primera estrategia de investigación, en fases sucesivas y destinada a poner cierto orden en los enfoques heredados. Se comenzó haciendo la Carta Arqueológica de Canarias, para tener una representación objetiva de los yacimientos y los objetos muebles; a continuación, estudios tipológicos de unos y otros; y, finalmente, excavaciones en lugares de hábitat, para reconstruir la vida del aborigen y no sólo su muerte, y que permitieran obtener secuencias estratigráficas donde observar la evolución cultural de las sociedades prehistóricas. Aquella labor eminentemente arqueográfica generó información suficiente para abrir múltiples perspectivas a la investigación y plantear modelos de interpretación en el futuro.

Las casi tres décadas transcurridas han significado un constante incremento de arqueólogos canarios y, evidentemente, con profundos cambios de índole metodológica. Si en los setenta las influencias de la escuela histórico-cultural y el neopositivismo alemán eran todavía claras, a comienzos de los ochenta tuvo lugar una transformación notable, prácticamente una ruptura. A partir de entonces cambió mucho la manera de investigar en Canarias, asistiéndose a una constante y rápida renovación, de forma que actualmente no existe en el Archipiélago un enfoque monolítico de la disciplina. Existen, eso sí, algunas tendencias predominantes, en las que unos pocos se incluyen de manera explícita y otros no lo hacen, pero lo demuestran. No podemos negar que aún quedan no pocos resabios de neopositivismo y normativismo, pero desde la década pasada un amplio sector de investigadores empezaron a decantarse, sobre todo, hacia la arqueología procesual y la ecología cultural, el materialismo histórico, el estructuralismo y, más que nada, una cierta variabilidad de posturas eclécticas.

La singularidad de la arqueología canaria estriba, sobre todo, en el objeto de estudio y, de manera subsidiaria, en las estrategias de investigación. Cuando aquí se habla de arqueología nos referimos básicamente a la arqueología prehistórica o prehispánica, porque la histórica tiene todavía escasa implantación. Se trata de estudiar unas sociedades que habitaban un archipiélago y, además, alejado de los antiguos circuitos de relaciones, por lo que no se pueden buscar los mismos modelos ni los mismos procesos culturales que hallamos en ámbitos continentales, como se intentó en otra época de manera infructuosa. A ello se añade el hecho de la insularidad, en relación al cual la investigación demuestra que cada isla tuvo una dinámica social y cultural propia, hasta que fueron conquistadas por los europeos en el siglo XV. Por eso, la escala insular acaba siendo, en definitiva, el ámbito natural de los proyectos, aunque los haya también de escala archipielágica. 
Las líneas de trabajo más activas - y no necesariamente por el mismo orden-son la etnohistoria, arqueología del territorio, bioantropología, paleoeconomía, tecnologías, manifestaciones rupestres y secuencias culturales. Últimamente empiezan a descollar la arqueología de la religión y la arqueoastronomía.

Disponemos de amplias y variadas fuentes escritas contemporáneas a la conquista 0 inmediatamente posteriores a ella, que constituyen valiosos documentos para conocer muchos aspectos de aquellas sociedades, sobre todo en lo referido a la estructura social y religiosa, pero también sobre otras muchas cuestiones. Eso estimuló a algunos investigadores a basar su trabajo en la interpretación de las fuentes etnohistóricas, con resultados sin duda interesantes (R. González y A. Tejera, 1981 y 1990; A. Tejera, 1988 y 1992; J.J. Jiménez, 1991; J.C. Cabrera, 1992), aunque también se les ha imputado el ignorar a veces la documentación arqueológica, y el caer ocasionalmente en la especulación y teorización excesivas (C. del Arco, 1982; C. del Arco et alii, 1992).

Superadas las viejas cartas arqueológicas de los años setenta, ya en los noventa alcanza bastante fuerza la arqueología del territorio, de manera que múltiples proyectos tienen como finalidad el estudio integral de un espacio, incluyendo programas de prospecciones y excavaciones de sitios seleccionados de acuerdo a los objetivos. Pero el reto consistía, no sólo en buscar un marco teórico, sino en diseñar una metodología de prospección y registro específica para la arqueología canaria, y el primer paso para ello se dio a lo largo de un extenso y enriquecedor debate en el seno del equipo que realizaba el inventario del Patrimonio Arqueológico de las Canarias Occidentales ${ }^{2}$. Se elaboraron unas primeras propuestas de sistema de registro, que fueron ensayadas en campo una y otra vez, mejoradas y puestas a punto durante años de prospecciones, para luego ser divulgadas entre los colegas, de forma que lo que hoy se hace en arqueología del territorio es heredero de aquel experimento, cuyos planteamientos han ido siendo superados (J.F. Navarro, C.M. Hernández y F. Álamo, 1995).

Entre 1973 y 1995 hubo una cierta intensidad de excavaciones en todas las islas y en el marco de diferentes proyectos, pero sobre todo La Palma, Tenerife y Gran Canaria, con unos sistemas de recuperación y

2 Navarro Mederos, J.F., Álamo Torres, F.; Hernández, C.M.; Valencia, V.; Mora, C.; TorRes, J.A.; Varela, P.; Febles, J.V.; Borges, E.; Rosa, F.J. De la; CuencA, A., et alii, 1989-1991: Inventario del Patrimonio Arqueológico de las Canarias Occidentales (IPACO). Gobierno de Canarias. Las propuestas se dieron a conocer en el pr Congreso de la Asociación Canaria de Arqueologia y Prehistoria (ACAP) (Las Palmas, 1990). 
registro cada vez más precisos. En los primeros años sólo se buscaban lecturas verticales, pero a fines de los setenta empezó a imponerse la idea de la excavación en extensión y se propugnaba la excavación integral de algunos yacimientos. Se ha excavado en Tenerife cavidades sepulcrales, cuevas de habitación, cabañas, talleres líticos, etc.; en La Palma numerosas cuevas de habitación y algunas necrópolis; en Gran Canaria poblados de superficie, algunas cuevas naturales y artificiales, así como necrópolis en túmulos y en cuevas; en el Hierro concheros, aras de sacrificio y cuevas-vivienda; en La Gomera concheros, cabañas y necrópolis; en Lanzarote y Fuerteventura poblados de superficie y sepulturas.

Merced a ello, se posee un cúmulo de información notable y, entre otras cuestiones, la vieja incógnita de la diacronía empieza a ser desvelada, ya que conocemos algunas secuencias, aunque con desigual intensidad por las diferentes islas. En La Palma se han llevado a cabo varios proyectos interrelacionados y se han excavado una docena de yacimientos con espectaculares depósitos estratigráficos, todo lo cual ha permitido desarrollar la más sólida tesis sobre el poblamiento y la evolución de las culturas (M.S. Hernández, 1978; J.F. Navarro y E. Martín, 1987; J.F. Navarro, E. Martín y A.C. Rodríguez, 1990; J.F. Navarro, 1991; E. Martín, 1992) (figura 2). En Tenerife se habían estudiado algunos interesantes yacimientos en los setenta y ochenta (L. Diego, 1979; M.C. Del Arco, 1985; B. Galván, 1991), y en la actualidad se trabaja con más intensidad y gran calidad en varios proyectos (C.M. Hernández et alii, 1996) ${ }^{3}$, lo que permite empezar a aclarar incógnitas. La monumentalidad de los yacimientos de Gran Canaria y las inversiones en su patrimonio superan con mucho al resto del Archipiélago, pero no así la investigación, que últimamente ha bajado en intensidad, por lo cual las hipótesis formuladas años atrás sobre la existencia de varios horizontes culturales (C. Martín, 1984, 1986 y 1988), distan mucho de poder ser comprobadas. Por último, en Lanzarote, la estratigrafía de un yacimiento es la base para una primera hipótesis sobre el poblamiento de la isla (P. Atoche et alii, 1989; P. Atoche, 1995), que resta contrastar en otros sitios.

Uno de los primeros problemas, que empezaron a detectarse en las modernas excavaciones canarias, fueron los confusos resultados del C-14.

La prehistoria de Tenerife carecía hasta ahora de una lectura discrónica de los procesos. El problema empieza a tener visos de solución gracias a recientes excavaciones de la Universidad de La Laguna, como las de B. Galván en Santiago del Teide y en varios yacimientos de Buenavista del Norte, y las de C.M. Hernández y V. Alberto en Candelaria. Desde el Museo Arqueológico se han iniciado otras en Tegueste. 


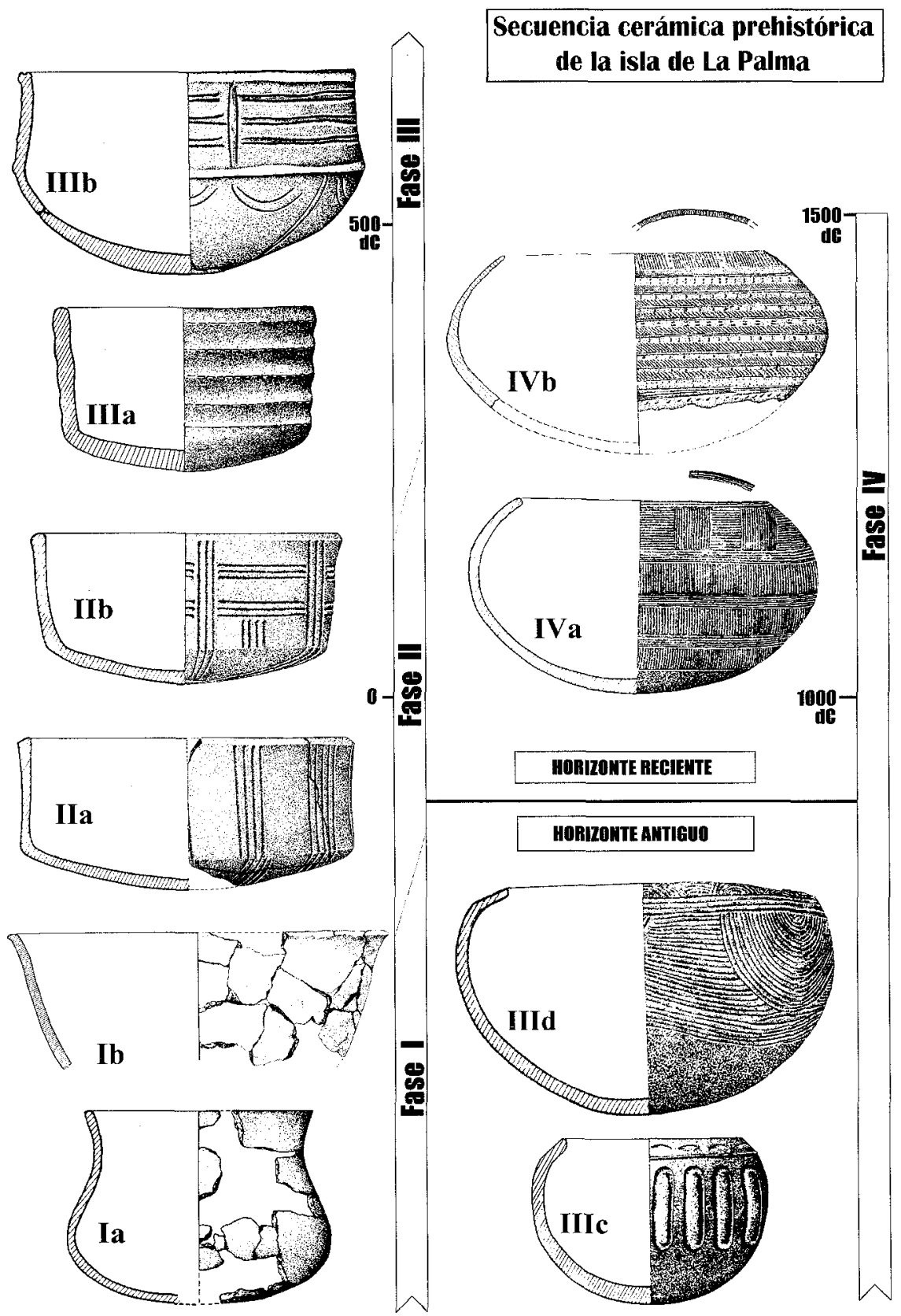

Figura 2. Evolución de la cerámica prehistórica de la isla de La Palma. 
Niveles que necesariamente eran contemporáneos arrojaban fechas muy dispares y, además, algunas dataciones estaban aparentemente muy rejuvenecidas. Esto hizo sospechar la existencia de agentes contaminantes, de los que hoy ya conocemos algunos. Por eso se comenzaron a ensayar procedimientos de datación alternativos, como el paleomagnetismo, la termoluminiscencia, etc., gracias a la estrecha colaboración interdisciplinar con la Estación Volcanológica del CSIC en La Laguna (V. Soler et alii, 1987), que está dando excelentes resultados.

Desde que el Gobierno Autónomo asumió las competencias en materia de cultura y patrimonio, las dotaciones para investigación, dentro de su parquedad, fueron crecieron progresivamente, y por fin se había conseguido que las intervenciones quedaran enmarcadas en proyectos plurianuales, evaluados por una Comisión Asesora, luego Ponencia Técnica. Las excavaciones habían disminuido en número, pero mejorado en calidad, porque así lo aconsejaba la propia investigación y la lógica de las cosas; pero también por los actuales avatares administrativos. En 1995 cesaron repentinamente las tradicionales convocatorias anuales. Ello ha coincidido con la transferencia de la mayoría de esas competencias a los Cabildos Insulares, que las ejercen a través de sus Unidades de Patrimonio y/o el personal de sus Museos, quienes realizan casi todas las intervenciones «de urgencia» y también las regulares, con fondos de la propia Corporación ${ }^{4}$. Las funciones de la Dirección General de Patrimonio Histórico han quedado bastante reducidas, aunque se reserva la de conceder autorizaciones, concedidas según su criterio y sin asesorarse por la Ponencia Técnica. Mientras, las dos Universidades, que hasta ahora habian llevado el peso de la investigación, han quedado fuera del sistema, y sus posibilidades de obtener financiación quedan reducidas a eventuales convenios para temas puntuales.

La consecuencia inmediata de todo ello es un freno en la investigación y el colapso de algunos proyectos, mientras que otros se sostienen a pesar de todo. A la vez, se han potenciado las excavaciones $u$ otras actividades accidentales en el marco de lo que podríamos llamar «arqueología de gestión”.

La bioantropologia, como antes hemos dicho, es una disciplina que en Canarias ha tenido una tradición de siglo y medio, pero en los últimos

4 Hay cierta desproporción entre los recursos que destina cada cabildo para arqueología. Los de Tenerife y Gran Canaria están a la cabeza, con una gran diferencia sobre el resto, la mitad de los cuales ni siquiera contempla el patrimonio arqueológico en sus presupuestos y, mucho menos, la investigación. 
tiempos se ha producido una renovación e intensificación, gracias a que se han consolidado equipos interdisciplinares estables y por la gran disponibilidad de material de estudio, tanto óseo como de otros tejidos conservados por procesos de momificación. De ahí que sea grande el abanico de especializaciones: antropología dental, paleonutrición, marcadores de actividad, paleopatología, antropología genética, a las que se añade el concurso de la arqueología funeraria y antropología del terreno (J.A. Torres, 1996). Actualmente existen en Canarias dos equipos: uno amplio en la Universidad de La Laguna, en el que están involucrados miembros de cuatro Facultades (M. Arnay et alii, 1987 y 1988; E. González Reimers et alii, 1989 y 1991; J. Velasco et alii, 1996), y otro que actúa desde el Museo Arqueológico de Tenerife con el respaldo técnico de especialistas norteamericanos (C. Rodríguez Martín, 1990; VVAA, 1994).

Una activa línea de investigación es la economía prehistórica y los estudios de paleoambiente, muy vinculado al mencionado enfoque ecológico de la cultura (C. del Arco, 1982; E. Martín, 1987; C. Del Arco, M.C. Jiménez y J.F. Navarro, 1992). En el marco de esta línea, se ha logrado potenciar la formación de profesionales en disciplinas como la zooarqueología, paleobotánica (C. Del Arco, 1993) y sedimentología, con diversas especializaciones en las evidencias mastológicas (F.J. Pais, 1992 y 1996), ictiológicas (J. Desse y C.G. Rodríguez, 1993; C.G. Rodríguez, 1997), malacológicas, antracológicas (M.C. Machado, 1994 y 1996), etc.

El estudio de las tecnologías ha conocido un viraje metodológico claro, pero los avances en el conocimiento son bastante disimétricos. Por ejemplo, en el caso de la cerámica, hay una útil sistematización morfométrica para la isla de Tenerife (M. Arnay y E. González, 1984 y 1987), empieza a estudiarse la de Lanzarote (P. Atoche, 1992) y La Gomera (J.F. Navarro, 1992), y se conoce la evolución de la cerámica de La Palma (J.F. Navarro y E. Martín, 1987; E. Martín, 1992). En las restantes islas es necesaria una sistematización actualizada, que urge más aún si cabe en el caso de Gran Canaria. En situación similar se encuentran los tejidos, madera, pieles, industria ósea y malacológica. Pero debemos reconocer que los mayores logros se han producido en la línea de investigación sobre la producción lítica, desarrollada por un equipo consolidado desde hace años en la Univ. de La Laguna. Destacamos su enfoque de análisis dentro de la economía prehistórica, como instrumentos de producción, con incidencia en las estrategias de aprovisionamiento, procesos de transformación de las materias primas y, en los últimos años, análisis funcionales (B. Galván, I. Francisco y A. Rodríguez, 1987; A.C. Rodríguez, 1993a y 1993b; B. Galván y C.M. Hernández, 1997; C.M. Hernández y B. Galván, 1997). 
En la década de 1970 se produjeron los primeros trabajos metódicos y sistematizaciones sobre las manifestaciones rupestres (A. Beltrán, 1971; L. Diego, 1973; A. Beltrán y J.M. Alzola, 1974; M.S. Hernández, 1975, 1978 y 1981). A partir de los ochenta se produjo un relevo en los investigadores, se reanudó el trabajo de campo en las islas tradicionalmente estudiadas, como La Palma, El Hierro y Gran Canaria. Pero el avance mayor se produjo en aquellas cuyo arte rupestre era hasta entonces desconocido, como Tenerife y La Gomera. Si antes se tenía ya la perspectiva de un arte diversificado, hoy los corpora han crecido enormemente y se ha acentuado la complejidad (A. Tejera, 1988; E. Martín, J.F. Navarro y F.J. Pais, 1990; M.C. Jiménez, 1991; E. Martín, 1992; y, sobre todo, VVAA, 1996). A esto hay que añadir los apasionantes logros y consecuencias de los estudios de epigrafía aborigen, tanto en lo que se refiere a las inscripciones líbico-bereberes (R. Springer, 1994), como a los numerosos epígrafes recientemente descubiertos en las dos islas orientales, en los que se usó una escritura cuya filiación hoy es objeto de debate (W.Pichler, 1992) (figura 3).

Por último, el campo de la arqueología histórica no consigue consolidarse de manera definitiva, a pesar de algunos intentos por abrir esta vía (J.F. Navarro, 1987; A. Tejera y E. Aznar, 1989) y, aunque hoy se han multiplicado las intervenciones arqueológicas en sitios históricos, salvo algunas excepciones, suelen estar supeditadas a proyectos arquitectónicos de rehabilitación del patrimonio y a estudios específicos de arqueología funeraria (J. Cuenca et alii, 1992; M. Arnay y J.A. Torres, 1992; C.M. Hernández et alii, 1996). No obstante, están en marcha las primeras Tesis sobre materiales históricos, que esperamos tengan continuidad. En peores condiciones aún ha estado la arqueología subacuática.

\section{EL PROBLEMA DEL POBLAMIENTO PREHISTÓRICO}

\subsection{Una prehistoria «reciente»}

Los niveles arqueológicos más antiguos hasta ahora identificados no van más allá de la mitad del ler milenio a.C. Es posible que algún día se demuestre presencia humana en las islas con anterioridad a esas fechas, pero de momento no es así. Por tanto, la prehistoria de Canarias abarcaría un espacio temporal que iría desde un momento impreciso en el milenio I a.C. hasta la definitiva conquista castellana a finales del siglo $x \vee$ d.C., en que se impuso un nuevo orden, una nueva cultura y comenzaría la "historia». Hasta no hace mucho, algunos prehistoriadores peninsulares se 

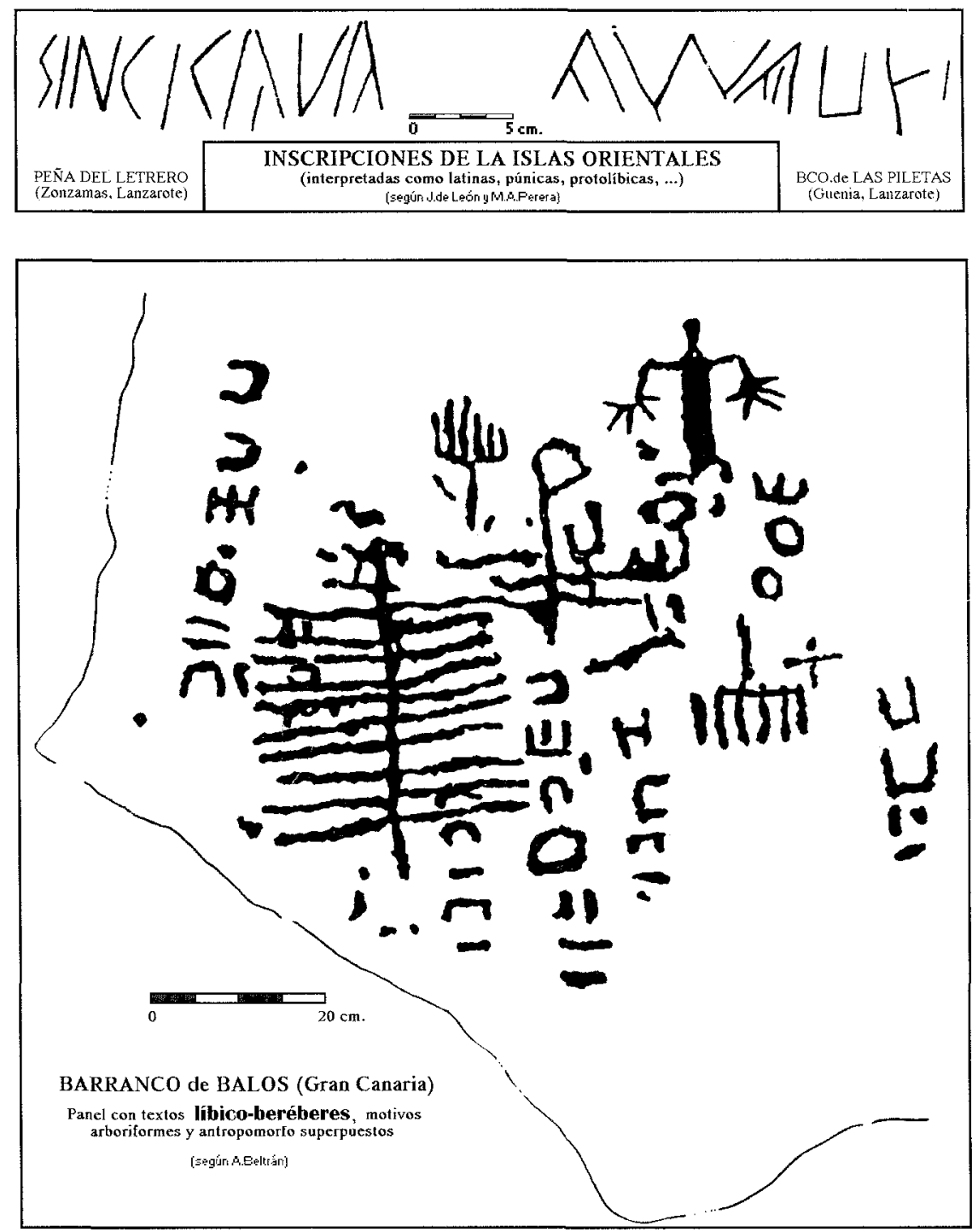

GRABADOS RUPESTRES: ALFABÉtIteOS

Figura 3. Una muestra de los dos grandes grupos alfabéticos existentes en Canarias.

sorprendían cuando se empleaba el término «prehistoria» para referirse a un espacio temporal que nada tenía que ver con el de la prehistoria europea. De hecho, no pocas veces se ha suscitado el debate interno sobre la 
propiedad del término, teniendo en cuenta que en algún momento todavía impreciso hizo su aparición en las islas la escritura, por lo que alguno ha propuesto usar "protohistoria», aunque todavía esos textos estén por descifrar con cierta fiabilidad. De hecho, hoy consideramos que la protohistoria canaria es ese corto período de contactos, en el que otras gentes ya escriben sobre los aborígenes, como abajo indicaremos. Durante un tiempo fue empleada como alternativa la expresión "prehispánico», tomada de la arqueología americana, pero a fines de los setenta muchos veían en ella connotaciones inaceptables, y se aminoró su empleo sin desaparecer. Otras propuestas, como "época precolonial», «historia antigua», etc. tienen un uso restringido. Finalmente, acabó manteniéndose de momento «prehistoria», porque ninguna alternativa ha resultado aceptable.

La destrucción de aquellas culturas no fue un fenómeno tan brusco como pudiera parecer. Desde fines del siglo XIII los europeos habían redescubierto el Archipiélago, comenzando así un período de contacto o "protohistoria", en el que ya se generaron ciertos procesos de aculturación que en algunas partes, como Gran Canaria, seguramente fueron mayores porque estuvo establecida allí una comunidad de mallorquines; mientras que en otras zonas estarían más atenuados. Ese período tuvo una duración variable, ya que la conquista franco-normanda de las islas orientales se inició en 1402 y las restantes fueron ocupadas de manera escalonada a lo largo de casi un siglo ${ }^{5}$. Luego, la cultura de los indígenas, más o menos contaminada, pervivió durante algún tiempo, en la medida que se mantuvo su modelo económico en algunas comarcas nada o escasamente colonizadas por los recién llegados, y es probable que en algunas pocas áreas marginales, como buena parte de La Gomera, esa situación se dilatara al menos hasta el $\mathrm{s}$. XVII.

\subsection{La búsqueda de los orígenes}

Probablemente en pocas partes sucede lo que en Canarias, donde ha habido desde siempre un interés social por el origen de las antiguas poblaciones, en su mayor parte de manera espontánea, aunque con variada intensidad según las épocas. Evidentemente, una de las razones esenciales es la búsqueda de la identidad y que los canarios sentimos, en diferente grado, que tenemos ciertos vínculos con quienes estaban aquí antes de la conquista. Por tanto, el interés es proporcional a ese sentimiento y

5 La última, Tenerife, fue conquistada por Castilla en 1496. 
aumenta más aún con el despertar del nacionalismo. Por eso es un tema de interés general, que suele trascender al terreno de lo político y que, en consecuencia, puede ser manipulable en una dirección u otra, como ha sucedido en varios momentos de nuestra historia.

Los cronistas y primeros historiadores de la conquista ya habían advertido que las formas dialectales y muchos otros aspectos de las culturas indígenas que ellos conocieron, recordaban bastante a la manera de hablar y a algunas costumbres de pueblos mazigios ${ }^{6}$ o bereberes de la época del vecino continente. Por tanto, el origen norteafricano de las antiguas poblaciones canarias, con todos los matices que puedan introducirse, es algo que ha estado siempre claro y que a lo largo de un siglo y medio no han hecho más que confirmar cada vez más la arqueología, la filología y la antropología.

En algunos momentos del pasado, este viejo convencimiento ha quedado momentáneamente eclipsado por fugaces modas, inspiradas en coyunturas de diverso cariz, que buscaban en otra parte los orígenes. Nuestro rusoniano J.Viera y Clavijo volvió a resucitar el manoseado mito de la Atlántida y convirtió a los guanches en los últimos atlantes, de igual estirpe que los héroes homéricos; pero enseguida las generaciones siguientes volvieron a mirar a África. En los albores del siglo xx, el anciano J. Bethencourt Alfonso no pudo sustraerse a la tentación de emparentar a los guanches y bereberes con los celtas, que el espíritu de la época había colocado en tan alta estima; pero el tiempo volvió a dejar a celtas e imazighen en sus respectivos continentes. Por último, en la década de los noventa, en las puertas del milenio, han brotado, como por ensalmo y con mucho ímpetu, los espontáneos que hacen disparatadas interpretaciones de la prehistoria canaria; o quienes dicen haber descubierto huellas arqueológicas de las más pintorescas culturas, colectividades y hasta fenómenos paranormales, que sólo ellos han visto.

Las pruebas lingüísticas relacionan con el mundo protobereber y bereber. Tenemos, por un lado, las listas más o menos extensas de vocablos y algunas frases, que transcribieron los relatores de la conquista con sus respectivas equivalencias al castellano; en segundo lugar están

6 Tradicionalmente se viene usando el vocablo «bereber» (plural «bereberes»), derivado de la denominación que los árabes dieron a los indígenas norteafricanos, pero ellos se llaman a sí mismos «imazighen" (en singular «amazigh"). Por tanto, a lo largo del texto los usaremos indistintamente, así como el adj. castellanizado «mazigio», para referirnos a los grupos étnicos magrebíes no árabes. Además, empleamos los términos «protobereberes» o «bereberes antiguos», cuando aludimos específicamente a sus ancestros preislámicos del ler milenio a.C. y primeros siglos de la Era, que entraron en contacto con las grandes civilizaciones mediterráneas. 
los antropónimos, etnónimos y topónimos que añaden las fuentes documentales; por último, un porcentaje alto de la toponimia mayor y menor actual es de origen prehispánico-mazigio, siendo hoy en día objeto de estudio por varios especialistas. Aunque, no debemos perder de vista que esas formas dialectales son las que había en el momento epigonal de aquellas culturas, y no sabemos cómo hablaban uno o dos milenios antes.

A ello se añade que, desde el siglo $x \mid x$, no han parado de descubrirse inscripciones con escritura líbico-bereber (figura 3), ampliamente difundidas por el Archipiélago, donde se han identificado varios alfabetos ( $R$. Springer, 1994), lo que redunda en la variabilidad del poblamiento.

La organización social y religiosa que nos describen las fuentes remite directamente a modelos norteafricanos. Lo mismo sucede con el material arqueológico y antropológico. Basándose en estos dos últimos, entre 1938 y 1960, aproximadamente, tuvo bastante aceptación la tesis de que el primer poblamiento canario se había producido hacia el 2500 a.C., protagonizado por cromañoides neolíticos portadores de una "Cultura de las Cuevas" norteafricana, que ocuparían todas las islas y, más tarde, vendrian otras oleadas de mediterranoides inmersos en la "Cultura Mediterránea», que se distribuirían de forma heterogénea por el Archipiélago; a eso se añadían posibles llegadas de navegantes del Bronce Atlántico a puntos muy concretos. $Y$ esa era la explicación a la diversidad arqueológica: en unas islas se habría mantenido con más fuerza el sustrato neolítico norteafricano, mientras que en las islas orientales, particularmente, en Gran Canaria se observarían más improntas mediterráneas con diversas filiaciones (figura 4). Por tanto, de una parte, se buscaban los paralelos en culturas neolíticas norteafricanas, como el mencionado Neolítico de las Cuevas, cuyas semejanzas se encontraron en muchas partes del Archipiélago, y el Neolítico de Tradición Capsiense, que se creyó ver reflejado en Tenerife (figura 7). De otra, se rastreaban paralelismos para Gran Canaria y algunos elementos concretos de otras islas, a lo largo de todo el Mediterráneo, desde culturas neolíticas hasta el Bronce. $Y$, a los petroglifos de La Palma se les buscaba el parentesco a lo largo de la fachada atlántica europea (figura 5).

Luego, empezó a comprenderse que muchas cosas no encajaban en ese esquema y, cuando empezó a emplearse el C-14, la antigüedad propuesta dejó de sostenerse y todo se vino a abajo. Se había olvidado que el Maghreb también está en el Mediterráneo y, aunque la prehistoria y protohistoria norteafricana está mal estudiada, se conoce lo suficiente como para no necesitar ir mucho más lejos. 

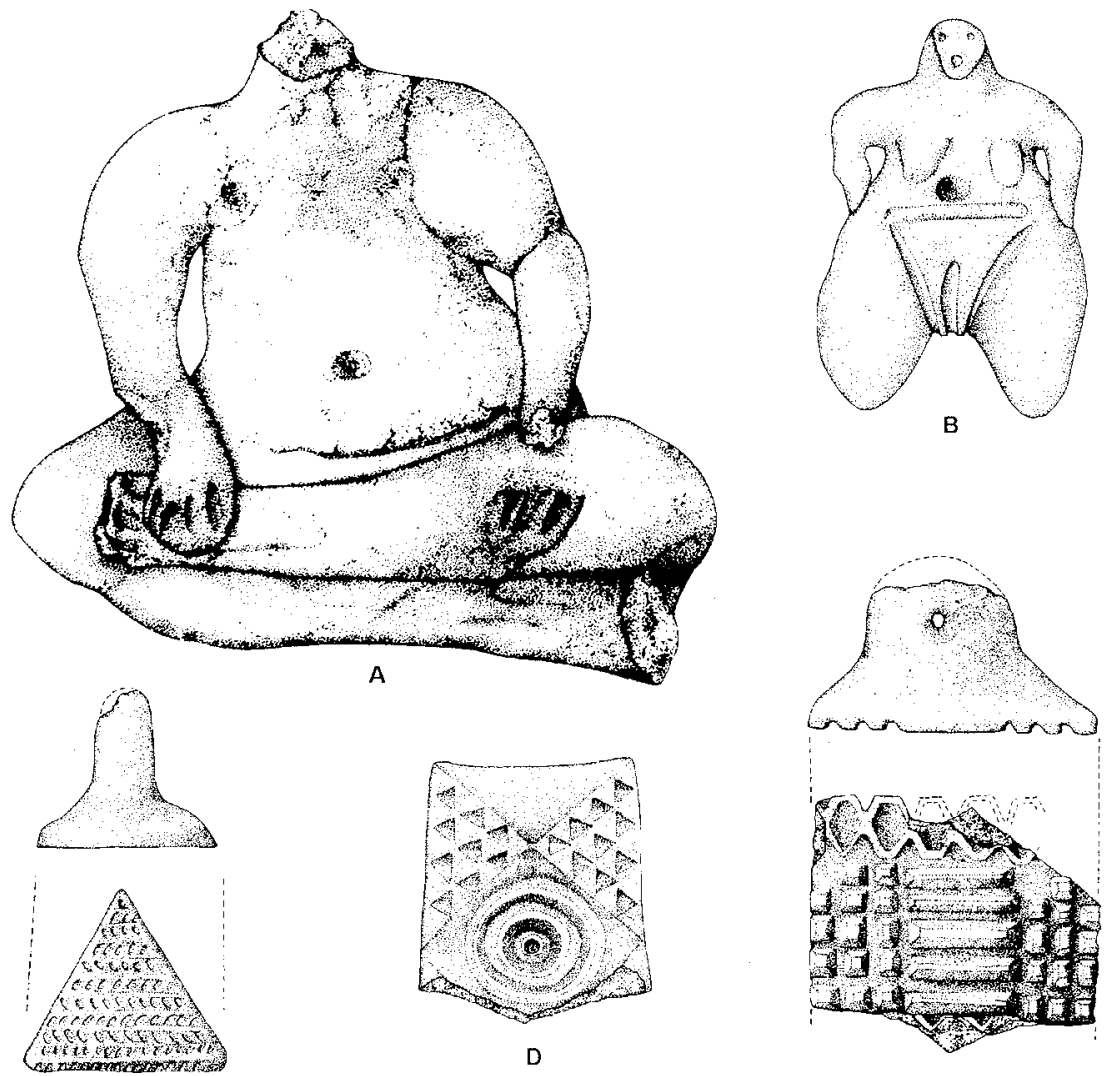

C

D

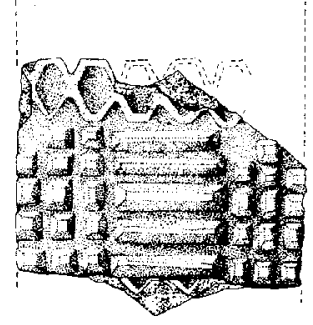

E
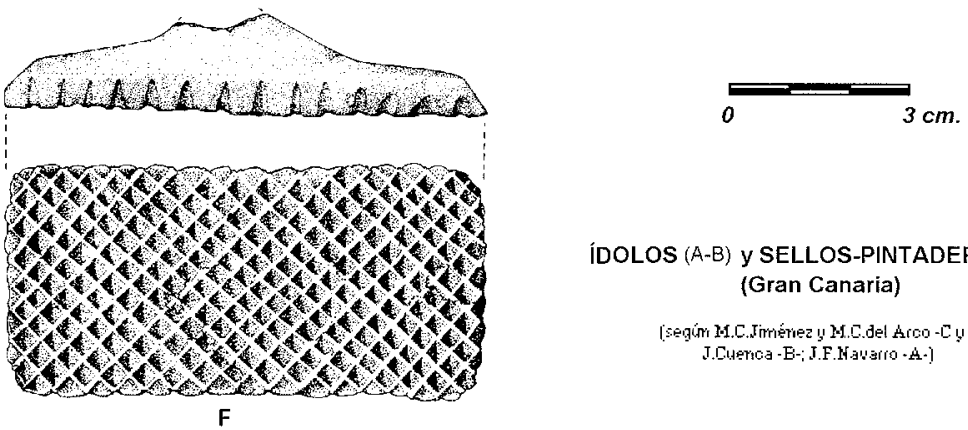

ÍDOLOS (A-B) y SELLOS-PINTADERAS (C-F) (Gran Canaria)

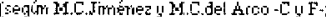

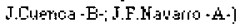

Figura 4. Las Figurillas (antropomorfas y zoomorfas, llamadas comunmente «ídolos») y los sellos de cerámica grancanarios, fueron relacionadas en el pasado con el neolítico del Mediterráneo Oriental, tesis hoy superada. 

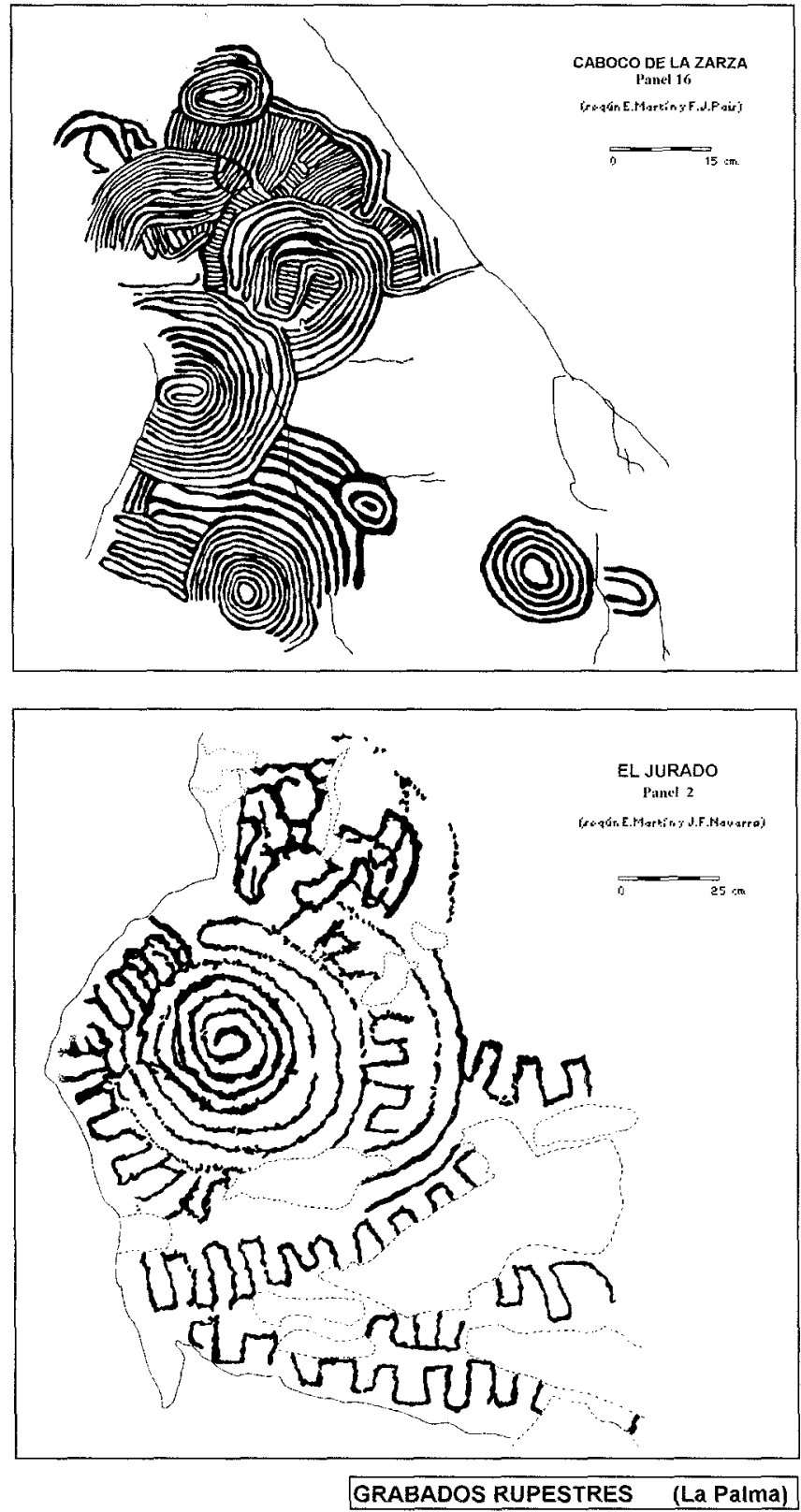

Figura 5. Los grabados geométricos de La Palma fueron emparentados con la Europa Atlántica, pero hoy se valora la via norteafricana. 
2.3. Conjeturando sobre las causas y medios del poblamiento.

Se ha debatido hasta la saciedad sobre las causas y los procedimientos del poblamiento canario, como es habitual en el caso de las islas, y sobre todo en unas cuyos habitantes no eran navegantes a la llegada de los europeos. Pero era un esfuerzo inútil seguir especulando sobre ello, mientras se desconociera la evolución cultural de cada isla y, por eso, algunos hemos defendido la necesidad de profundizar en los procesos diacrónicos, en lo cual ha sido pionero y casi exclusivo el equipo que viene investigando en la isla de La Palma (M.S. Hernández, 1978 y 1984; J.F. Navarro y Martín, 1987; J.F. Navarro, E. Martín y A.C. Rodríguez, 1990; E. Martín, 1992).

Los grupos humanos que llegaban a Canarias lo hacian con la intención de instalarse, porque trajeron todo lo necesario para ello, como el ganado y las semillas para cultivar. Los motivos para ello pudieron ser varios: ecológicos, económicos, estratégicos, sociales, políticos, ideológicos, etc.

La progresiva desecación del Sahara y el consiguiente aumento de la sequedad en el Maghreb ha sido un proceso largo, que desde el milenio I a.C. ha evolucionado muy lentamente y de manera poco perceptible. Pero sus pequeñas pulsaciones han influido en los movimientos migratorios africanos, como actualmente tenemos la oportunidad de comprobar, aumentando la presión antrópica sobre las tierras más fértiles, a la vez que favoreciendo algunos desplazamientos y tensiones intergrupales. De hecho, hemos comprobado que a La Palma recalaron gentes de origen sahariano alrededor de los siglos IX o $\times$ d.C., coincidiendo con un período de aparente sequedad en la isla; $y$ actualmente empiezan a aparecer indicios de ciertos cambios climáticos en el Sahara por esas fechas.

El estado Cartaginés presionó territorialmente sobre los indígenas de su entorno inmediato, e impuso tributos y reclutamientos a protobereberes orientales, que reaccionaban con revueltas. Pero con los occidentales los contactos fueron más superficiales, aunque había fondeaderos hasta el Estrecho de Gibraltar y alguna colonia más al Sur. Por tanto, no puede descartarse que los cartagineses tuvieran conocimiento y contacto con las Canarias, e incluso que se interesasen en algún momento por su control, pero de eso no hay constancia escrita ni testimonios arqueológicos fidedignos. Desde que T. Bravo y M. García Borges encontraran hace más de cincuenta años varias cuentas de material vítreo en cuevas de Tenerife ${ }^{7}, y$

7 Información del Prof. Telesforo Bravo y Miguel A.Clavijo Redondo. 
creyeran que eran fenicias, hasta hoy, no han cesado los intentos por encontrar pruebas de la presencia de fenicios y cartagineses en las islas, pero siempre de manera infructuosa. En la actualidad, un grupo de investigadores se esfuerzan en encontrarlos, y relacionan con ello la llamada «Piedra Zanata» y un supuesto santuario rupestre (R. González et alii, 1996) ${ }^{8}$. En fin, existe la probabilidad de que los púnicos intervinieran en el poblamiento de Canarias, pero sería conveniente contar con pruebas de su presencia más fidedignas.

La ocupación romana del Norte de África tuvo un impacto muy superior y muchos pueblos indigenas se resistieron con múltiples levantamientos armados entre los siglos I a.C. y III d.C., que fueron sofocados violentamente y seguidos a menudo por deportaciones masivas o de las élites guerreras. Sabemos que a principios del s. I a.C. unos marinos gaditanos describieron a Sertorio dos islas que parecen Lanzarote y Fuerteventura, y años más tarde Juba II de Mauritania, un maghrebí romanizado, envió una expedición a reconocer el Archipiélago. La presencia romana en aguas del Archipiélago está documentada, como hemos dicho, a través de unos pocos hallazgos de ánforas de épocas distintas (G. Escribano y A. Mederos, 1996), e incluso un yacimiento de Lanzarote aportó unos poco fragmentos cerámicos que su excavador considera romanos (P. Atoche, 1989).

En el siglo VII comenzaron las incursiones árabes, a menudo con gran virulencia, que en los siglos posteriores llegarían a alcanzar niveles muy exacerbados por motivos religiosos. Algunos grupos imazighen sin islamizar o tibiamente islamizados fueron perseguidos por su heterodoxia religiosa, al menos hasta el siglo XV. Es muy probable que en ese tiempo se desplazaran nuevas gentes a las islas, como se ha propuesto para La Palma.

Hemos defendido que los medios para llegar a Canarias pudieron ser tanto propios como ajenos, sin que debamos excluir ninguno de los dos. En el supuesto de haber usado sus propios medios, contemplamos dos variables: 1) que lo hicieran voluntariamente, con la intención de instalarse o con otra, pero con ese resultado; 2) que llegaran accidentalmente, por error, por una navegación de fortuna, posibilidad que no se descarta, aunque nunca habría tenido un papel destacado como motor del poblamiento. El empleo de medios ajenos ha sido el argumento más cómodo para explicar el por qué

- El supuesto santuario es un grupo de rocas que hace años fueron arrastradas por una máquina, y las estrías producidas por el deslizamiento han sido interpretadas como grabados. $\mathrm{E} \mid$ escándalo ha rodeado a la piedra Zanata desde que un particular la vendió al Museo de Tenerife como originaria de un lugar, que otros testigos negaban. Luego se propuso la lectura "ZN" (zanata) de los dos signos grabados en una de sus caras, lo cual ha sido rebatido por los más reputados especialistas en inscripciones líbico-bereberes; que no descartan fueran hechos recientemente. 
los canarios desconocían la navegación o tenían conocimientos de ella muy rudimentarios. También aquí caben dos variables: 1) fueron traídos voluntariamente, con la intención de establecerse; 2) los trajeron a la fuerza, es decir deportados, procedimiento que usó Roma en el continente. Un trabajo reciente (R. González et alii, 1996) va en esa línea, al especular con que los púnicos vendrían a explotar las pesquerías de túnidos, y traerían pastores y agricultores indigenas para su abastecimiento, pero lo cierto es que no hay pruebas de tales factorías ni de la pesca de túnidos.

Un caso singular de encendido debate, espoleado por intereses extracientíficos, es el de las morras de Chacona (Güimar, Tenerife), unas construcciones de piedra volcánica, en forma de pirámides escalonadas (figura 6 ), de las que hubo otras muchas en la isla. Su monumentalidad ha despertado el interés social, ciertas expectativas económicas en su entorno y un debate periodístico de proporciones sólo parangonables al del caso anterior. Sobre ellas han especulado aficionados a la historia, a las ciencias alternativas y a temas esotéricos, y un sector del nacionalismo, todos los cuales quieren demostrar que sus autores fueron los guanches. Thor Heyerdhal se interesó por el asunto, ya que sus tesis incluian a Canarias en el circuito trasatlántico que, según él, habrían recorrido hasta Mesoamérica los adoradores del sol que construían observatorios astronómicos piramidales. La hipótesis de antropólogos, arqueólogos e historiadores canarios, basada en estudios previos, era que estas y otras manifestaciones análogas de Lanzarote y La Palma sirvieron para acumular ordenadamente las piedras, al poner en cultivo en época histórica esos terrenos volcánicos muy pedregosos pero fértiles. La demanda social empujó a un equipo de la Universidad de La Laguna a colaborar con el antropólogo noruego en un proyecto común, con excavaciones que confirmaron nuestras hipótesis y una antigüedad de menos de dos siglos (M.C. Jiménez y J.F. Navarro, 1995). Pero las especulaciones continúan como si nada hubiera pasado.

\section{SIETE PREHISTORIAS}

Los exploradores medievales y los conquistadores observaron que las culturas de cada isla tenían muchas singulares dentro del conjunto, existiendo incluso diferencias abismales en algunos $\operatorname{casos}^{\circ}$; les sorprendió

\footnotetext{
9 Los europeos captaron enseguida esa variabilidad. Pero, cuando en el proceso de conquista grupos de indígenas de una isla ocupada fueron llevados a otra por conquistar, como intérpretes o como tropas auxiliares, ellos mismos detectaron las diferencias que les separaban. El
} 


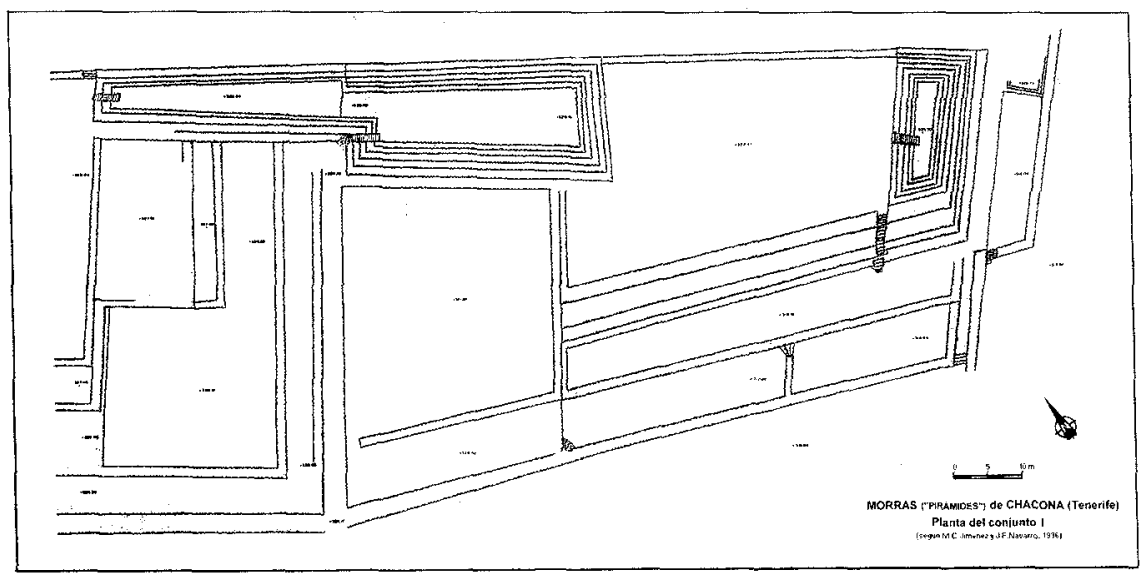

Figura 6. Los majanos construidos por nuestros campesinos, que ahora algunos rebautizan como "pirámides", se usan para apoyar determinadas tesis difusionistas.

que su lengua pareciera ser la misma, pero hablaban formas dialectales distintas, de manera que al principio les costaba entenderse entre ellos; $y$ que incluso su aspecto físico, aún siendo análogo, variaba algo de unas islas a otras ${ }^{10}$. La arqueología confirma hoy esa heterogeneidad. Una visión rápida de las evidencias arqueológicas, nos pone de manifiesto que existen notables diferencias entre las islas (figura 7). Luego, si nos detenemos más, observaremos que, tras esa primera impresión, en muchas manifestaciones es posible encontrar parentescos, que están bien claros en unos casos y en otros bastante desdibujados ya. Mientras que, por el contrario, hay elementos que son claramente distintos de unas islas a otras. Eso significa que, al margen de que todas o muchas de las islas hubieran estado involucradas en un mismo proceso colonizador, luego cada una de ellas quedó inmersa en su propia dinámica interna. Como ya hemos señalado, de momento sólo conocemos con precisión la secuencia cultural y de poblamiento de La Palma, y empezamos a tener detalles parciales para otras.

caso más conocido es el de los canarios (de Gran Canaria) que se esforzaban por no ser confundidos con guanches, gomeros y benahoaritas (palmeros), cuyas culturas y costumbres consideraban muy ajenas a las suyas, e incluso «inferiores».

10 A título de ejemplo, los relatores de la conquista destacan algunas particularidades, como la gran estatura de palmeros, canarios y majoreros (Fuerteventura); la piel clara y aspecto robusto de los palmeros; la altura relatívamente baja de los gomeros, análoga a la de los propios castellanos; etc. Cuestiones que la moderna antropología biológica se ha encargado de confirmar. 
Las causas de la variabilidad cultural entre las islas hay que atribuirla a la combinación de procesos exógenos (migración, contactos) y endógenos (dinámica interna). Con lo que sabemos, creo que es factible aceptar una primera migración, que se distribuyó por las islas, probablemente de manera escalonada y en un tiempo breve. Luego siguió un proceso de adaptación, colonización de los respectivos territorios, aislamiento y formación de las culturas insulares. Entretanto, se debieron producir contactos con visitantes externos, generalmente discontinuos, que a lo mejor durante un tiempo fueron regulares y en otros momentos de forma irregular; en unos casos afectando a toda la colectividad, y quizás en otros con cierta discriminación, por ejemplo beneficiando a la oligarquía local. Pero todo esto es difícil de detectar.

Ya hemos mencionado la posibilidad indemostrada todavía de que los fenicios occidentales tuvieran algún contacto. De los primeros navegantes que hay testimonios arqueológicos, aunque muy parcos y controvertidos, es de romanos y/o norteafricanos romanizados, cuyo contacto posiblemente facilitara el desarrollo de algún rasgo tecnológico o ideas de otro tipo. Pero no sería un tráfico regular y constante, ni éstos llegaron a fundar establecimientos de carácter estable, o al menos no han aparecido, a pesar de los ímprobos esfuerzos por encontrarlos.

En algún/os momento/s se produjeron otras nuevas inmigraciones, que en unos casos pudieron ser duras, en otros blandas, etc., y que posiblemente no afectaron a todas las islas. Una de ellas ha sido detectada en La Palma hacia fines del milenio I de la Era (J.F. Navarro y E. Martín, 1987), y otras han sido sugeridas para Gran Canaria (C. Martín, 1984 y 1988).

Buena parte de la diversidad canaria puede deberse a la variabilidad cultural norteafricana de origen. Los pueblos magrebies y saharianos del fer milenio a.C. que describen los textos clásicos, presentaban una notable diversidad cultural, cuestión que la arqueología se ha encargado de confirmar y ampliar. De hecho, incluso los imazighen actuales siguen constituyendo un complejo entramado cultural, en el que hasta su propia lengua, que constituye el mayor nexo entre todos los grupos, en realidad es pluridialectal.

Pero a esto se añaden otros procesos históricos. En términos hipotéticos, suponiendo que una misma arribada afectara a más de una isla, el impacto cultural en cada una de ellas no sería necesariamente igual, porque: A) La distribución de un mismo contingente de población por varias islas no tuvo por qué ser equitativa en composición, cualificación, etc. B) El impacto cultural de los recién llegados sería diferente según hubiera o no gente ya instalada; según el nivel de consolidación del grupo ya establecido, su receptividad frente a extranjeros e ideas nuevas, y la capacidad de 

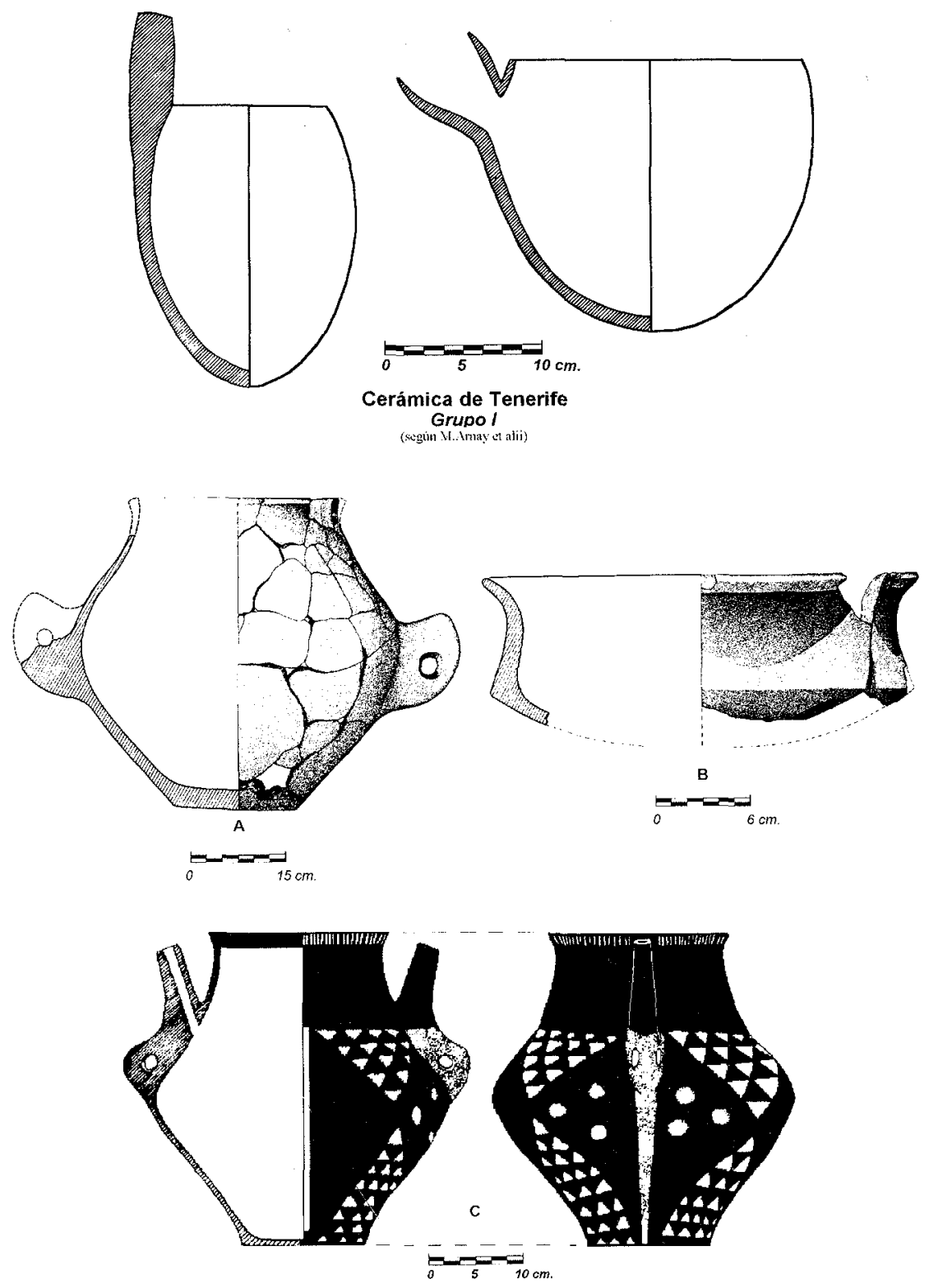

Cerámica pintada de Gran Canaria

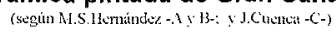

Figura 7. La cerámica es uno de los elementos donde más se detecta la variabilidad interinsular. 
imposición de un grupo sobre el otro; en definitiva, dependería en buena medida del sistema de relaciones que se establecieran entre ambos. Por ejemplo, en Tenerife existía un mito de origen social (A. Tejera y R. González, 1987; A. Tejera, 1988), según el cual la preeminencia del grupo dominante sobre el dependiente, que no tenía derechos sobre los medios de producción, se justificaba míticamente porque Dios los había puesto a ellos primero sobre la tierra, dándoles todo el derecho sobre el terreno y el ganado, y más tarde creó a los otros, que tuvieron que trabajar al servicio de los anteriores. No descarto la posibilidad de que este mito enmascare la arribada a la isla de un nuevo grupo, cuando el anterior ya se ha apropiado del derecho sobre el territorio y tiene medios para imponerlo a los recién llegados, que para sobrevivir deben asumir una situación de dependencia.

Sin embargo, concedemos más importancia a los factores endógenos, de manera que los habitantes de cada isla fueron desarrollando sus propios modelos adaptativos, sus estrategias de explotación y, con el paso del tiempo, fueron evolucionando en gran medida de manera autónoma, y cada vez más alejados del resto de los isleños. Los pobladores tenían como base de partida su bagaje tecno-cultural de origen, pero fueron ajustándolo a su nueva situación social, y a las condiciones ambientales de cada territorio ${ }^{11}$.

Un ejemplo de lo anterior lo encontramos, como ya hemos dicho, en La Palma donde, desde el primer poblamiento humano, comenzaron a producirse transformaciones culturales y ecológicas ${ }^{12}$. Los lentos procesos de cambio cultural que caracterizan al Horizonte Antiguo ${ }^{13}$ fueron debidos mayoritariamente a causas endógenas, pero posiblemente también algún rasgo tecnológico pudo deberse a contactos externos. Cinco siglo antes de la conquista llegaron nuevos contingentes de población de origen sahariano, que provocaron transformaciones culturales muy perceptibles ${ }^{14}$.

\footnotetext{
Existen notables diferencias ecológicas de unas islas a otras.

12 De entrada, la presencia humana en la isla debió contribuir a la desaparición de algunas especies animales, como los lagartos gigantes, según se observó en la excavación del Roque de Los Guerra. La introducción de especies domésticas (cabras, ovejas, cerdos, perros, ...) y el desarrollo del pastoreo generó algunos cambios en el medio.

13 Los primeros pobladores, posiblemente procedian del Maghreb occidental y, al instalarse en la isla desarrollan una cultura en lenta evolución, que hemos denominado Horizonte Antiguo, el cual se iniciaría hacia 1/2 ler milenio a.C. y duró hasta los últimos siglos del jer milenio d.C. En esos más de mil años la cerámica va cambiando, de tal manera que hemos distinguido hasta tres fases o estilos sucesivos, a su vez divididos en subfases. Lo mismo sucede con los grabados geométricos.

14 Con ellos se inaugura nuestro Horizonte Reciente, con un nuevo estilo cerámico (Fase IV), algunos cambios ideológicos (aparición de idolillos, crisis de los grabados, etc.) e incluso sociales (transformaciones en los patrones de asentamiento).
} 
Ese aislamiento podía haber quedado mitigado si hubiese existido una navegación regular y masiva entre las islas. Pero no fue así y, a lo sumo, lo que pudo existir en tiempos inmediatamente anteriores a la conquista, fueron travesías esporádicas y con embarcaciones muy elementales. La tradición oral recogió citas de travesias entre Tenerife, La Gomera y El Hierro usando balsas de odres inflados; y hay una dudosa descripción de canoas hechas en Gran Canaria con corteza de drago. En 1988 identificamos ${ }^{15}$ en La Palma un grabado (figura 8 ) que recuerda determinadas embarcaciones de la antigüedad, integrado en un conjunto de espirales y meandros que, de ser realmente un barco y no sólo parecerlo ${ }^{16}$, sería el primer motivo figurativo que observamos inmerso en un contexto de grabados geométricos de esta isla. En época histórica ya empiezan a ser numerosos los grabados de barcos, realizados por pastores tradicionales, probablemente aborígenes en su mayoría, de los que el de la figura $8 \mathrm{~b}$ es posiblemente uno de los ejemplares más antiguos.

Lo antes dicho no quiere decir que los indígenas no navegasen o que siempre fuera en las condiciones descritas; aunque, de hecho, existen ciertas dificultades técnicas en la navegación interinsular, y probablemente los canarios en origen nunca fueron un pueblo de grandes navegantes. Pero empiezan a existir algunos pocos indicios arqueológicos de conexiones entre islas, como una pieza de obsidiana identificada en La Gomera y que pudiera ser originaria de Tenerife. Por otra parte, los indígenas de La Palma tenían calculada la cantidad de personas que la isla podía sostener y, una vez alcanzada esa cifra, se sacrificaba a los recién nacidos y a todos aquellos que arribaran por el mar, lo cual quiere decir que esto se produciría de vez en cuando, quizás sólo navegantes de paso, quizás verdaderas inmigraciones desde el continente $y$, por qué no, desde otras islas.

\section{ORIENTACIÓN BIBLIOGRÁFICA}

\subsection{Revistas especializadas}

- Tabona. Revista de prehistoria y arqueología (Departamento de Prehistoria, Antropología e Historia Antigua, Universidad de L.a Laguna). Desde 1972.

\footnotetext{
15 En el marco del proyecto "Corpus de Grabados Rupestres de la isla de La Paima (Canarias)» (E. Martín, J.F. Navarro y F.J. Pais, 1990)

16 Los grabados prehistóricos son abundantísimos en La Palma. La inmensa mayoría se adscriben al grupo de ideogramas geométricos (espiraliformes, meandriformes, circuliformes, lineales y reticulados), como sucede en este caso. A menudo, los intrincados trazos y composiciones se asemejan vagamente a cosas concretas, pero siempre es una semejanza formal producto de una
} 
- Investigaciones Arqueológicas en Canarias (Dirección General de Patrimonio Histórico, Gobierno de Canarias). Desde 1988.

- Eres (serie arqueológica) (Museo Arqueológico de Tenerife, Cabildo Insular). Desde 1990.

\subsection{Revistas misceláneas}

- El Museo Canario (Museo Canario, Las Palmas de Gran Canaria). Desde 1880.

- Revista de Historia Canaria (Facultad de Geografía e Historia, Universidad de La Laguna). Desde 1924.

- Anuario de Estudios Atlánticos (Museo Casa Colón-CSIC, Las Palmas-Madrid). Desde 1956.

- Almogaren (Institutum Canariarum, Hallein, Austria) Desde 1970. Su contenido es mayoritariamente arqueológico.

- Vegueta (Facultad de Geografía e Historia, Universidad de Las Palmas de Gran Canaria). Desde 1992.

\subsection{Monografias regionales}

Arco Aguilar, M.C.; Jiménez Gómez, M.C., y Navarro Mederos, J.F., 1992: La arqueología en Canarias: del mito a la ciencia. $\mathrm{S} / \mathrm{C}$ de Tenerife.

Navarro Mederos, J.F., y Del Arco Aguilar, M.C., 1987: Los aborígenes. Historia Popular de las Islas Canarias, 1 . $\mathrm{S} / \mathrm{C}$ de Tfe.

TeJera GaSPAR, A., y GonZÁlez ANTón, R., 1987: Las culturas aborígenes canarias. S/C de Tenerife (Interinsular Canaria).

\subsection{Monografías insulares}

Cabrera Pérez, J.C., 1992: Lanzarote y los Majos. Colección «Prehistoria de Canarias», 4. $\mathrm{S} / \mathrm{C}$ de Tenerife (Centro de la Cultura Popular Canaria).

Cabrera PÉrez, J.C., 1993: Fuerteventura y los Majoreros. Colección «Prehistoria de Canarias", 7. S/C de Tenerife (Centro de la Cultura Popular Canaria).

DiEgo Cuscoy, L., 1968: Los Guanches. Vida y cultura del primitivo habitante de Tenerife. S/C de Tenerife.

González Antón, R., y Tejera Gaspar, A., 1990: Los aborígenes canarios. Tenerife y Gran Canaria. Madrid.

JiMÉNEZZ GÓMEZ, M.C., 1993: El Hierro y los Bimbaches. Colección «Prehistoria de Canarias», 6. $\mathrm{S} / \mathrm{C}$ de Tenerife (Centro de la Cultura Popular Canaria).

JIMÉNEZZ GONZÁLEZ, J.J., 1990: Los Canarios. Etnohistoria y arqueología. S/C de Tfe.

JIMÉNEZ GONZÁLEZ, J.J., 1992: Gran Canaria y los canarios. Prehistoria de Canarias (Centro de la Cultura Popular Canaria), 2. S/C de Tfe.

MARTín DE GuZMÁn, C., 1984: Las culturas prehistóricas de Gran Canaria. Las Palmas.

Martín Rodriguez, E., 1992: La Palma y los ahuaritas. S/C de Tenerife (Centro de la Cuitura Popular Canaria).

Navarro Mederos, J.F., 1992: Los gomeros: una prehistoria insular. S/C de Tenerife (Viceconsejería de Cultura y Deportes. Gobierno de Canarias).

percepción selectiva. ¿Podría ser este el caso, o de veras estamos ante un barco? En este resbaladizo mundo, donde tantas interpretaciones erróneas se han producido en el pasado, toda la cautela es poca. 

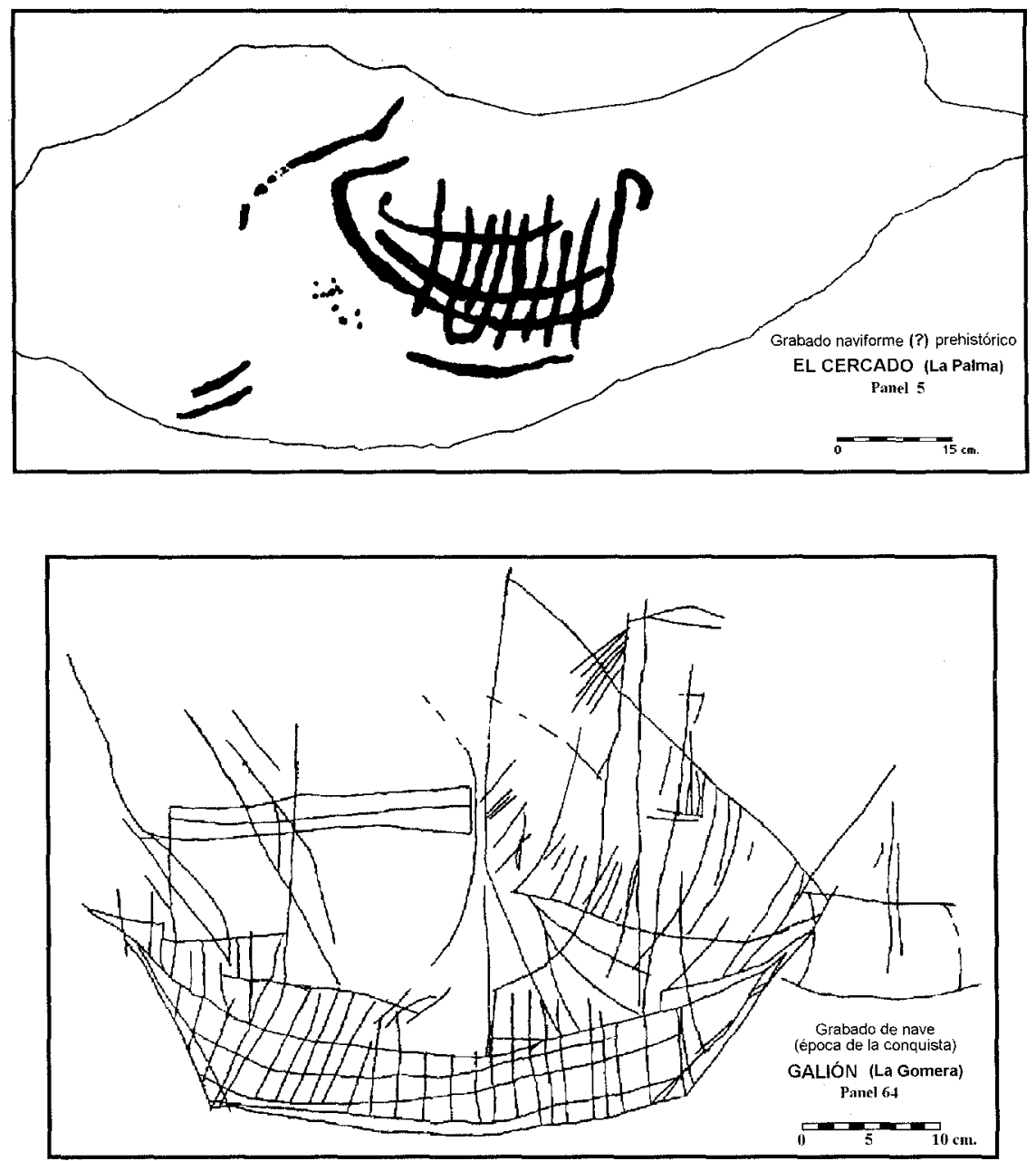

GRABADOS RUPESTRES: EMBAREAGIOHES

Figura 8. Grabados rupestres con motivos naviformes, prehistórico e histórico.

Navarro Mederos, J.F., 1993: La Gomera y los gomeros. Colección «Prehistoria de Canarias", 5. S/C de Tenerife (Centro de la Cultura Popular Canaria).

Tejera Gaspar, A., 1992: Tenerife y los guanches. S/C de Tenerife (Centro de la Cultura Popular Canaria). 


\subsection{Selección de publicaciones sobre temas más específicos}

ARCo AgUILAR, M,C, 1982: Aproximación a la economía aborigen de Tenerife. 50 Aniversario del Instituto de Estudios Canarios, II, S/C de Tenerife, págs. 51-87

Arco Agullar, M,C, 1985: Excavaciones en la Cueva de don Gaspar (Icod de los Vinos, Tenerife). Noticiario Arqueológico Hispanico, 20, Madrid, págs. 259-377.

ARco Agullar, M.C., 1993: De nuevo el enterramiento canario prehispánico. Tabona, VIII, págs. 59-75.

ArCo AgulLAR, M.C., 1993: Recursos vegetales en la prehistoria de Canarias. S/C de Tenerife.

ARNAY de LA ROSA, M., y GonzÁlez Reimers, E., 1984: Vasos cerámicos prehispánicos de Tenerife: un análisis estadístico. Anuario de Estudios Atlánticos (Madrid-Las Palmas), 29, págs. 79-107

ARnAy de la Rosa, M., y GonzÁlez Reimers, 1987: La cerámica decorada prehispánica de Tenerife. Tabona, VI, págs. 241-277.

arnay de la Rosa, M.; González Reimers, E.; Galindo, L., y Del Valle, V., 1987: Oligolementos y masa ósea en los cadáveres prehispánicos de El Portillo (Tenerife): aportación al conocimiento de la dieta aborigen. Tabona, VI, págs.458-464.

arnay de la Rosa, M.; González Reimers, E.; Galindo, L., y Del Valle, V., 1988: Bone strontium contents in the population of the Canary Islands. Journal of Anthropology, 3. Firenze.

arnay de LA Rosa, M., y TORRES PaLenzUelA, J. A., 1992: Excavación arqueológica de la Iglesia de Na Sra de la Concepción, Santa Cruz de Tenerife. Investigaciones Arqueológicas en Canarias, 4, págs. 199-216.

Atoche PeÑA, P., 1992: Análisis morfométrico y funcional de los recipientes cerámicos de los antiguos habitantes de Lanzarote. Investigaciones Arqueológicas en Canarias, 3, págs. 39-81.

Atoche Peña, P., Rodríguez, M.D., y Ramírez, M.A., 1989: El yacimiento arqueológico de «El Bebedero". S/C de Tenerife.

Beltrán Martínez, A., 1971: Los grabados rupestres del Barranco de Balos. Zaragoza.

Beltrán Martínez A., y Alzola González, J.M., 1974: La Cueva Pintada de Gáldar. Zaragoza.

CoRTÉs VÁzQUEZ, M., 1987: Los petroglifos podomorfos de la Montaña de Tindaya: características formales y significación. I Jornadas de Historia de Lanzarote y Fuerteventura (Puerto del Rosario), II, págs. 13-63.

CUENCA SANABRIA, J. et alii, 1983: Trabajos en pieles y fibras vegetales de los aborígenes canarios. Catálogo de la exposición del mismo nombre. Las Palmas.

CUENCA SANABRIA, J. et alii, 1992: La investigación histórico-arqueológica del desaparecido Convento de San Francisco de Las Palmas de Gran Canaria. Investigaciones Arqueológicas en Canarias, 4, págs. 9-198.

Desse, J., y Rodríguez Santana, C.G., 1993: La arqueoictiología: investigaciones preliminares en Canarias. Tabona, VIII, tomo l, págs. 117-137.

Diego Cuscoy, L, 1972: D.Elías Serra Ráfols y la época heróica de la arqueología canaria. Rev. de Historia Canaria, XXXIV, págs. 14-19.

Diego Cuscoy, L., 1973: El Roque de Teneguía y sus petroglifos. Noticiario Arqueológico Hispánico (Prehistoria), 2, págs. 57-141.

Diego Cuscoy, L, 1977: Notas para una historia de la antropología canaria. Historia General de las Islas Canarias, de A. Millares Torres, I, S/C de Tenerife, págs.267-290.

Diego Cuscor, L., 1979: El conjunto ceremonial de Guargacho. S/C de Tenerife.

Diego CuscoY, L., y Galand, L., 1975: La Necrópolis del Hoyo de los Muertos (Guarazoca, El Hierro). Noticiario Arqueológico Hispánico (Madrid), 4. págs.11-33.

DiEgo Cuscoy, L. et alii, 1960: Trabajos en torno a la cueva sepulcral de Roque Blanco. S/C de Tenerife (Cabildo Insular).

Escribano Cobo, G., y Mederos Martin, A., 1996: ¿Ánforas romanas en las Islas Canarias? Revisión de un aparente espejismo histórico. Tabona, IX, págs. 75-97.

Esteban, C., Belmonte, J.A., y Aparicio, A., 1994: Canarias: del legado escrito a la evidencia arqueológica. Arqueoastronomía Hispánica, capítulo 6. Madrid (Sirius).

ETÉVEZ GONZÁlEZ, F, 1987: Indigenismo, raza y evolución. El pensamiento antropológico canario (1750-1900). S/C de Tfe.

Fusté ARA, M., 1962: Diferencias antropogeográficas en las poblaciones de Gran Canaria. Anuario de Estudios Atlánticos (Madrid-Las Palmas), 8, págs. 67-86.

Fusté ARA, M., 1962: Estudio antropológico de los esqueletos inhumados en túmulos de la región de Gáldar (Gran Canaria). EL MUSEO CANARIO, 77-84 (1961-62), págs. 1-122. 
Galván Santos, B., 1979: Breve ensayo de sistematización tipolóqica de la industria ósea de los aboriqenes canarios. XV Congreso Nacional de Arqueología, Madrid, págs. 337-346.

Galván SANTOS, B., 1980: El trabajo del junco y la palma entre los canarios prehispánicos: $R e-$ vista de Historia Canaria (La Laguna), XXXVIII, págs.43-81.

Galván Santos, B. (1991): La Cueva de Las Fuentes (Buenavista del Norte Tenerife), I. S/C de Tenerife.

Galván Santos, B.; Rodriguez Rodriguez, A.C., y Francisco Ortega, I., 1987: Propuesta metodológica para el estudio de las industrias líticas talladas prehistóricas canarias. Tabona, VI, págs. 9-89.

GalvÁn SAntos, B., y HeRnÁndez Gómez, C.M., 1996: Aproximación a los sistemas de aprovisionamiento y transformación de las industrias líticas canarias. Tabona, $I X$, págs. 45-74.

GARcí, Carlos, 1993: Las enfermedades de los aborigenes canarios. S/C de Tenerife (Centro de la Cultura Popular Canaria).

González Antón, R.; Balbín, R.; Bueno, P., y Del Arco, M.C., 1996: La piedra Zanata. S/C de Tenerife.

González Antón, R., y Tejera Gaspar, A., 1986: Interpretación histórico-cultural de la arqueología del Archipiélago Canario. Anuario de Estudios Atlánticos, 32 (Madrid-Las Palmas), págs. 683-697.

González Reimers, E., Arnay, M.; Galindo, L.; Del Valle, V.; Jorge, J., y Santaolaria, F., 1989: Oligoelementos en el hueso del aborigen canario: consideraciones acerca del regimen dietético de los mismos. $V$ Congreso Nacional de Antropología Biológica, León.

González Reimers, E.; Arnay, M.; Galindo, L.; Batista, N.; Navarro, J.F.; Castro, V., y SanTOLARIA, F., 1991: Trabecular bone mass and bone content of diet-related elements among the Prehispanic inhabitants of the western Canary Islands. Human Evolution, VI, 2. Firenze, págs.177-188.

Hernández Gómez, C.M.; Alberto, V.; Barro, A.; Borges, E.; Eugenio, C.M.; Velasco, J.; Rivero, M.D.; Matos, L.; Febles, J.V., Larraz, A., y González, M.C., 1996: Las cuevas de Achbinicó (Candelaria, Tenerife): un proyecto de arqueología prehistórica e histórica. El Museo Canario, LI (Las Palmas), págs. 29-58

HeRnÁndez Gómez, C.M., y Galván SANTOS, B., 1997: Materias primas y fuentes de aprovisionamiento de recursos líticios en la prehistoria de Tenerife (Islas Canarias). 2a Reunió de treball sobre aprovisionament de recursos lítics a la prehistòria (Barcelona-Gavá), 15 págs.

Hernández Pérez, M.S., 1975: Pinturas y grabados rupestres del Archipiélago Canario. Historia de Canarias de A.Millares Torres, I. S/C de Tenerife, págs. 323-338.

Hernández Pérez, M.S., 1978: La Palma prehispánica. Las Palmas.

HeRnÁndez PÉREZ, M.S., 1980: El poblamiento prehispánico de las Islas canarias. recientes aportaciones. I/ Coloquio de Historia Canario-Americana. Las Palmas, págs. 15-46.

HeRnández PÉREz, M.S., 1981: Algunas consideraciones sobre la cronología del arte rupestre canario. Altamira Symposium (Santander). 495-504.

HeRnÁNDEZ PÉREZ, M.S., 1984: Estado actual de la investigación sobre el Archipiélago Canario prehispánico. $V$ Coloquio de Historia Canario-Americana, págs. 9-31.

JIMÉNEZ GómeZ, M.C., 1981: Aspectos generales de la prehistoria de Gran Canaria. El Museo Canario, $X X X V I I I-X L$, págs. 57-72.

JimÉnEz GómEZ, M.C., 1991: Magia y ritual en la prehistoria de El Hierro. Tabona, VII, págs. $159-172$.

Jiménez GómezZ, M.C., y DEL ARCo AgulLAR, M.C., 1984: Estudio de los ídolos y pintaderas de la Aldea de San Nicolás. Tabona, $V$, págs. 47-92.

Jiménez Gómez, M.C., y Navarro Mederos, J.F., 1996: El complejo de las Morras de Chacona (Güimar. Tenerife): Resultados del proyecto de investigación. Coloquio de Historia CanarioAmericano (Las Palmas, 1996).

JoRge Godoy, S., 1996: Las navegaciones por la costa atlántica africana y las Islas Canarias en la Antigüedad. Estudios Prehispánicos, 4. S/C de Tenerife.

Machado Yanes, M.C., 1994: Primeros estudios antracológicos en las Islas Canarias. Tesis Doctoral. Universidad de La Laguna.

MACHADO YANES, M.C., 1996: Approche paléoecologique et ethno-archéologique de site «El Tendal» (En de l'ile de La Palma, Archipel des Canaries), d'apres l'analyse anthracologique. Actes du 120 Congrès des Sociétés Historiques et Scientifiques. Aix-en-Provence.

MARTíN DE GUZMÁN, C, 1986a: La navegación en la fachada atlántica africana y Canarias. $V / C o-$ loquio de $H^{a}$ Canario-Americana. Las Palmas. 
MARTín DE GuZMÁN, C., 1986b: La arqueología prehistórica de Gran Canaria sometida al análisis estructural, VI Coloquio de Historia Canario-Americana (Las Palmas), págs. 7-88.

MARTIN DE GuzMÁN, C., 1988: El horizonte cultural «Cueva Pintada» y el sustrato mediterráneo (Ensayo de aproximación y estrategia epistemológica). VI Coloquio de Historia CanarioAmericana (Las Palmas, 1984), tomo 2,1, págs. 204-298.

martín de Guzmán, C., Onrubia Pintado, J., y Saenz Sagasti, J.l., 1992: Excavaciones en el Parque Arqueológico Cueva Pintada de Gáldar, Gran Canaria. Investigaciones Arqueológicas en Canarias, 4, págs. 307-346.

Martin Oval, M.; Arnay, R.; Ponte, E.; Zerolo, I., y Jiménez, M.C., 1987: Estudio preliminar de la fauna del Conchero de Guinea (Frontera, El Hierro). Tabona, Vi, págs. 227-240.

Martin Rodriguez, E., 1987: La economía prehistórica de la isla de La Palma. Un enfoque ecológico sobre la explotación del territorio. (Resumen de Tesis Doctoral). La Laguna.

Martín Rodriguez, E., 1993: Adaptación y adaptabilidad de las poblaciones prehistóricas canarias. Una primera aproximación. Vegueta, 1, págs. 9-19.

Martín Rodríguez, E., y Navarfo Mederos, J.F., 1984: El Barranco de San Juan y el Arte Rupestre palmero: un doble proyecto de investigaciones arqueológicas en la isla de La Palma. El Museo Canario, XLV, págs. 9-32.

Martín Rodriguez, E.; Navarro Mederos, J.F., y Pais Pais, F.J., 1990: El Corpus de Grabados Rupestres de la isla de La Palma como instrumento para el estudio y conservación de este tipo de manifestaciones. Investigaciones Arqueológicas en Canarias, II.

Navarro Mederos, J.F., 1987: Una experiencia de "Arqueología Histórica» en Canarias: la iglesia de La Asunción en San Sebastián de La Gomera. RHC, XXXVIII, Homenaje al profesor José Peraza de Ayala, vol.ll, págs.587-604.

Navarro Mederos, J.F., 1991: El poblamiento prehistórico. Historia de Canarias, I, Madrid (Ed. Prensa lbérica), págs. 41-60.

Navarro Mederos, J.F., Hernández Gómez, C.M., y Álamo Torres, F., 1995: Las manifestaciones rupestres de Tenerife: un enfoque desde la arqueología del territorio. I Symposium sobre manifestaciones Rupestres del Norte de Africa y Canarias (Las Palmas, 1995).

Navarro Mederos, J.F., y Miartín Rodriguez, E., 1987: La prehistoria de la isla de La Palma (Canarias): propuesta para su interpretación. Tabona, VI, págs.147-184.

Navarro Mederos, J.F.; Martín Rodríguez, E., y Rodriguez Rodriguez, A.C., 1990: La primera fase del programa de excavaciones arqueológicas en Cuevas de San Juan y su aportación a la diacronia de la prehistoria de La Palma. Investigaciones Arqueológicas en Canarias, /l, págs. 187-202.

OnRubia PINTADo, J., 1986: El complejo arqueológico de la Cueva Pintada de Gáldar (Gran Canaria). Estudio preliminar de los materiales exhumados en 1970. Noticiario Arqueológico Hispánico (Madrid), 28, págs. 243-285.

OnRuBiA PINTADO, J., 1987: Les cultures préhistóriques des îles Canaries. Etat de la question. L'Anthropologie, 91, $n^{\circ} 2$. Paris, págs. 653-678.

PaIs PaIS, F.J., 1992: Los estudios zooarqueológicos en la isla de La Palma. El Museo Canario, XLVIII (1988-1991), págs.11-18.

PAIS PAIS, F.J., 1996: La economía de producción en la prehistoria de la isla de La Palma: la ganadería. S/C de Tenerife (Viceconsejería de Cultura y Deportes del Gobierno de Canarias).

PICHLER, W., 1992: Die Schrift der Ostininseln. Corpus der Inschriften auf Fuerteventura. Almogaren, XXIII. Hallein, págs. 313-451.

Rodriguez Martin, C., 1990: Una perspectiva histórica de la paleopatología en Canarias. EresSerie Arqueológica, 1, págs. 21-50.

Rodríguez Rodríguez, A.C., 1993a: La industria lítica prehistórica de la isla de La Palma: Cuevas de San Juan, un modelo de referencia. Tesis Doctoral íntegra publicada en microfichas. La Laguna.

Rodriguez Rodríguez, A.C., 1993b: Analyse fonctionnelle d'outils lithiques en basalte de l'île de la Palma (îles Canaries): premiers résultats. Traces et fonction: les gestes retrouvés. Colloque international de Liège. Editions ERAUL, vol, 50, págs. 295-301.

Rodriguez SANTANA, C.G., 1996: La pesca entre los canarios, guanches y auaritas. S/C de Tenerife (Cabildo Insular de Gran Canaria).

SCHWIDETZKY, I., 1963: La población prehispánica de las Islas Canarias. S/C de Tenerife.

SPRINGER Bunk, R., 1994: Inscriopciones líbico-bereberes de las Islas Canarias. Tesis Doctoral. Universidad de La Laguna. 
TEjera Gaspar, A., 1986: Estado actual de las investigaciones arqueológicas en las Islas Canarias. VII Coloquio de Historia Canario-Americana (Las Palmas), págs. 259-296.

TEJERA GASPAR, A., 1988: La religión de los guanches. Ritos, mitos y leyendas. S/C de Tenerife.

TEJERA GASPAR, A., 1996: La religión de los gomeros. Mitos, ritos y leyendas. S/C de Tenerife.

TEJera GaSpar, A., y AzNAR VAllejo, E., 1987: El asentamiento franconormando de San Marcial del Rubicón (Yaiza, Lanzarote). S/C de Tenerife.

TORREs PALENZUELA, J.A., 1996: Arqueología de gestos funerarios y antropología del terreno: nuevas consideraciones para la investigación de yacimientos sepulcrales en Canarias. Tabona, IX, págs. 197-228.

Velasco VázQuez, J.; Arnay de la Rosa, M., y González Reimers, E., 1996: El estado nutricional de la población prehistórica de Gran Canaria: estudio de las líneas de Harris. Tabona, $I X$, págs. 229-238.

VVAA, 1994: Actas del Primer Congreso Internacional sobre estudio de momias. S/C de Tenerife.

VVAA, 1996: Manifestaciones rupestres de las Islas Canarias. S/C de Tenerife (Dirección General de Patrimonio Histórico). 417 págs. Contiene: A.Beltrán Martínez: Introducción. M.S. Hernández Pérez: Notas historiográficas. A. Tejera Gaspar y M.A. Perera Betancor: Fuerteventura. J. Cuenca Sanabria: Gran Canaria. J.J. Jiménez González: Tenerife. J.F. Navarro Mederos: La Gomera. E. Martín Rodríguez y F.J. Pais Pais: La Palma. M.C. Jiménez Gómez: El Hierro. R. Springer Bunk: Inscripciones alfabéticas líbico-bereberes. 